\title{
Effects of management and health on the use of activity monitoring for estrus detection in dairy cows
}

\author{
S. P. M. Aungier, ${ }^{\star}$ J. F. Roche, ${ }^{\star}$ M. Sheehy, ${ }^{*}$ and M. A. Crowe ${ }^{\star} \dagger^{1}$ \\ *School of Veterinary Medicine, and \\ †Conway Institute for Biomolecular and Biomedical Research, University College Dublin, Belfield, Dublin 4, Ireland
}

\begin{abstract}
The aim was to investigate 1) the relationship between the physical activity index created for each cow by activity monitoring systems and the identification of the preovulatory follicular phase, and 2) the influence of various production, health, and cow factors on the relationship between physical activity and estrous behavior. Eighty-nine spring calving cows, on pasture, were monitored during the breeding season using the neck-mounted estrous activity monitor Heatime (SCR Engineers Ltd., Netanya, Israel). Milk samples were collected twice weekly for progesterone assay to characterize resumption of reproductive activity. Reproductive tract health was assessed weekly by ultrasonography and vaginal mucus scoring. Body condition score and milk yield were assessed every 2 wk. Heatime identified $72 \%$ of preovulatory follicular phases from which 145 inseminations resulted in 69 conceptions; $32 \%$ of activity clusters were associated with high-progesterone states (i.e., false positives). By inclusion of a 6 to 8 -h duration threshold and maintaining the borderline peak activity threshold, this was improved to $87.5 \%$ with $21.3 \%$ false positives. Mean ( \pm standard error of the mean) peak activity and cluster duration (19.3 \pm 0.53 and $10.8 \pm 0.38$, respectively) were highest for the second or subsequent preovulatory follicular phases followed, in descending order, by those during first preovulatory follicular phases $(14.8 \pm 2.13$ and $8.4 \pm 1.4$, respectively) and high progesterone states $(8.0 \pm 0.47$ and $3.0 \pm 0.42$, respectively). The odds of an activity cluster being in a preovulatory follicular phase rather than a high-progesterone phase improved by $29 \%$ for every 1-unit increase in peak activity and by $91 \%$ for every 2 -h increase in duration. The probability of an activity cluster detecting a preovulatory follicular phase was improved if it was a second or subsequent follicular
\end{abstract}

Received June 24, 2011.

Accepted December 20, 2011.

${ }^{1}$ Corresponding author: mark.crowe@ucd.ie phase, if body condition score was 0.25 units higher, if milk yield was $10 \mathrm{~kg}$ lower, and uterine infection was absent. Conception rate was influenced by insemination on the same day (52\%) or day after a cluster (34.3\%); inseminations were carried out using the a.m.-p.m. rule. Advances in the development of more accurate automatic monitoring of the preovulatory follicular phase will aid the timing of insemination and, thus, improve conception rates.

Key words: activity cluster, estrous behavior, Heatime, dairy cow

\section{INTRODUCTION}

Reproductive efficiency in Holstein-Friesian cows has decreased over the last $25 \mathrm{yr}$ worldwide. Singletrait selection for increased milk production has caused about a $1.0 \%$ decrease per year in calving rate to first service in the UK (Royal et al., 2000). In seasonal pasture-based systems of milk production, such as occur in Ireland and New Zealand, the conception rate to first service is 39 to $52 \%$ (Dillon et al., 2006; Macdonald et al., 2008). In addition, dairy cows have decreased follicular estradiol production, which causes a shorter, less intense estrus (Wiltbank et al., 2006). In high-yielding dairy cows, the mean ( \pm SEM) duration of estrus is $6.2 \pm 0.5 \mathrm{~h}$ and cows are mounted approximately once per hour based on the use of HeatWatch (Lopez et al., 2004). High-yielding dairy cows have increased metabolic rate, which increases liver blood flow and may increase metabolism of estradiol-17 $\beta$ (Sangsritavong et al., 2002). It is thought that lower blood estradiol concentrations decrease the intensity of behavioral signs of estrus (Sangsritavong et al., 2002; Wiltbank et al., 2006). This has exacerbated the problems associated with estrous detection and, hence, has resulted in decreased submission rates when using AI (Lyimo et al., 2000). In comparison, nulliparous heifers had higher estradiol concentrations during the preovulatory follicular phase and this might account for the longer durations $(11.3 \pm 6.9 \mathrm{~h})$ and greater number of standing mounts $(16.8 \pm 12.8)$ 
than are seen in dairy cows (Nebel et al., 1997). To achieve high submission rates to AI, which are critical to achieve a 365-d calving interval in seasonal calving herds, requires an effective, practical means of identifying each cow in estrus. Standing to be mounted is considered the main behavioral sign identifying an estrous period and is used to determine the correct time to inseminate. Both the physical activity and mounting activity induced by increased estradiol production in the preovulatory follicular phase can be monitored in various ways. Visual observation of mounting activity for $20 \mathrm{~min} 3$ to 5 times per day results in 90 to 95\% submission rate (Diskin and Sreenan, 2000) but is laborious and time consuming. In Holstein-Friesian cows where behavioral signs of estrus were monitored every $3 \mathrm{~h}$, sniffing and chin resting were noted and $90 \%$ of estrous periods showed mounting and $58 \%$ were detected in standing estrus. Estrus was reported more intense in primiparous than in multiparous cows and when a sexually active group was formed (Roelofs et al., 2005). Attempts have been made to monitor changes in physical activity to predict estrus. The pedometer, either attached to a leg (S.A.E. Afikim, Kibbutz Afikim, Israel; Holman et al., 2011) or neck collar (Alpro; DeLaval International AB, Tumba, Sweden; Peralta et al., 2005), identifies increased physical activity as an activity cluster. Increased physical activity can be monitored as mounting behavior through use of systems such as the electronic device HeatWatch, scratch cards (e.g., Estrotect; Rockway Inc., Spring Valley, WI), color ampules (e.g., Kamar Products Inc., Zionsville, IN), vasectomized bulls fitted with a chin ball marker, and tail-painting methods (Diskin and Sreenan, 2000).

The relationship between the physical activity index created for each cow by activity monitoring systems and the identification of the preovulatory follicular phase is not well defined, nor is it clear how various production, health, and cow factors affect the relationship between physical activity and estrous behavior. Therefore, the aim was to address these questions to determine the factors that differentiate the occurrence of activity clusters, detected using Heatime activity monitors (infrared telemetry; SCR Engineers Ltd., Netanya, Israel), with or without an associated preovulatory follicular phase. The following hypotheses were examined: 1) in cyclic cows, the characteristics of an activity cluster depend on whether it occurs during a preovulatory follicular phase or not; 2) the likelihood of an activity cluster is associated with a preovulatory follicular phase and is affected by the cow's health status or physiological status, or both; and 3) the characteristics of an activity cluster will affect the conception rate to AI.

\section{MATERIALS AND METHODS}

\section{Study Animals}

The study was conducted between April and July 2009, during the breeding season, on a commercial dairy farm in County Kildare, Ireland. A total of 89 cows were chosen from the spring-calving cohort of the herd selected on the basis of having had single-calf births and calving after January 19. Similar numbers of cows, from different lactations, were divided up into 3 groups representing first lactation $(\mathrm{n}=27)$, second lactation $(\mathrm{n}=26)$, and a third group made up from lactations 3 to $8(\mathrm{n}=36)$. The total herd comprised 245 Holstein-Friesian cows. The calving period extended from January 19 to May 5, with a calving distribution of $22,19,34,13$, and 1 for months January through to May, respectively. During this time, lactating cows were housed to the end of March and from the start of April, all animals that had calved were on pasture with a neck band (SCR H-Tag; SCR Engineers Ltd.) activity monitor. All dry cows were fed a TMR of straw, corn silage, grass silage, and soybean meal (including a vitamin and mineral mix), and were housed until they calved. As the remaining cows calved, they received a monitor and joined the study group on pasture. Animals were milked twice daily and were offered a concentrate ration at these times. The study group had a 305 -d milk yield of $8,800 \pm 154 \mathrm{~kg}$ with an average peak yield of $43.9 \mathrm{~kg}$ and daily yield of $29.1 \mathrm{~kg}$ for 2009 to 2010. Ireland has a temperate climate and does not have extremes of temperature. Between April and the end of July 2009, the number of daylight hours ranged from 14 to $17 \mathrm{~h}$ and the weather was wet and mild, with rainfall ranging from 41 to $130 \mathrm{~mm}$ per month with temperatures ranging from $13^{\circ} \mathrm{C}$ in April to $19^{\circ} \mathrm{C}$ in July. The study was approved by the Animal Research Ethics Committee of University College Dublin (Ireland) and was licensed by the Department of Health and Children, Ireland, in accordance with the Cruelty to Animals Act (Ireland 1876) and European Union Directive 86/609/EC.

\section{Monitoring of Health and Physiological Status Postpartum}

Prior to the initiation of the study, serum samples were collected to monitor the herd for presence of 1) bovine viral diarrhea, 2) infectious bovine rhinotracheitis, 3) Salmonella Dublin and Typhimurium, 4) Leptospira hardjo, and 5) Neospora caninum. At calving, the incidence of dystocia, calving injuries, retained placenta, and milk fever was recorded. Reproductive 
status was monitored by rectal ultrasound scanning from $10 \mathrm{~d}$ postpartum on a weekly basis up to $\mathrm{d} 60$ in the case of cows that had resumed normal ovarian activity with neither metritis nor endometritis present. For cows that failed to get rid of either metritis or endometritis by d 60, ultrasound scanning continued until any uterine infection still present had resolved. At the same time as ultrasound scanning, vaginal mucus was assessed for odor and purulent exudate content as described previously (Sheldon and Dobson, 2004). Collection of a cytology brush sample from the wall of the uterine body was carried out once a noninfected vaginal mucus sample was obtained on 2 consecutive weekly analyses and cytology was carried out to assess subclinical endometritis. Body condition (Edmonson et al., 1989) and lameness scoring (Sprecher et al., 1997) were carried out every 2 wk from calving. Milk yield, protein percentage, butterfat percentage, and SCC were recorded twice monthly up to 100 DIM.

\section{Milk Sampling and Progesterone Analysis}

Whole milk samples were collected twice weekly on Tuesdays and Fridays at morning milkings into 30$\mathrm{mL}$ plastic sample bottles, preserved with a Lactab tablet (33 $\mathrm{mg}$ of potassium dichromate) and frozen at $-20^{\circ} \mathrm{C}$ until analyzed. Milk collection continued until an animal was diagnosed pregnant at approximately d 30 post-AI. Additional milk samples were collected on d 4, 5, and 7 post-AI. Samples were analyzed for milk progesterone concentration using a validated solid-phase RIA (Coat-A-Count Progesterone; Siemens Medical Solutions Diagnostics, Los Angeles, CA). The assay had a minimum detection limit of $0.05 \mathrm{ng} /$ $\mathrm{mL}$. The intra-assay coefficients of variation $(\mathrm{n}=6)$ for pooled milk samples containing $0.3,2.2$, and 10.1 $\mathrm{ng}$ of progesterone/mL were $21.5,10.1$, and $7.6 \%$, respectively. The interassay coefficients of variation (n $=13$ ) for the same milk samples were $22.0,16.3$, and $11.0 \%$, respectively. Progesterone concentrations were used to generate profiles to characterize resumption of reproductive activity postpartum and confirm the occurrence of interovulatory periods, during which estrus would be expected to occur. Detection was confirmed if milk progesterone decreased to below $0.6 \mathrm{ng} / \mathrm{mL}$ over 1 to 2 samples. Ovulation occurred if at least 2 consecutive milk samples were $\geq 0.6 \mathrm{ng} / \mathrm{mL}$. The total number of expected estrous periods for each animal could then be identified from this progesterone analysis (Figure $1 \mathrm{~A}$ and B). The cluster activities associated with both the developing, regressing, and pregnant corpora lutea were analyzed. Those clusters associated with both persistent corpora lutea and anovulatory states were not analyzed due to insufficient numbers.

\section{Infrared Telemetry (Heatime)}

All cows that had previously calved were fitted with an accelerometer tag attached to a neck collar as per manufacturer's instructions (Heatime; SCR Engineers Ltd.). Monitoring of a cow's activity started $14 \mathrm{~d}$ before she entered the trial to establish a baseline activity threshold. The accelerometer consisted of an acceleration sensor, microprocessor, memory, and an 8-yr lifespan battery and it monitored the head and neck movements of the animal to create a general physical activity index for each cow. This quantified all animal movement and movement intensity in 2-h time blocks. The 2-h blocks are shown by Heatime to demonstrate the intensity and duration of heat. The average of the last $8 \mathrm{~h}$ of activity was used. The greater the number of high 2-h blocks, the higher the 8-h average and vice versa. The memory stored data for up to $24 \mathrm{~h}$. An identification unit at the entrance to the milking parlor collected the data (via infrared communication) into a control unit, which could hold information for each cow for up to $60 \mathrm{~d}$. The data for the entire monitoring period was downloaded into Heatime software on a personal computer for analysis. The control box compared the current average 8-h period activity level to a normal baseline activity level established for the previous 7-d average activity level to identify increases in activity. The current average 8-h activity level was measured as standard deviations above or below this baseline. The Heatime system identified an animal in a preovulatory follicular phase if the current average activity level was $\geq 5$ standard deviations above baseline. A detailed graphic report of the activity of a cow was displayed on a screen to help determine whether the increased activity was estrus related. On the scatter plot (Figure 2A), peak activity level plateaued at 25 standard deviations. This is because the Heatime software does not register above this. When analyzing the time of occurrence of peak activity level during an activity cluster, any cluster with only 1 activity occurrence was considered a 0-h duration (Figure 2B). Heatime had a total of 252 activity clusters, of which 7 occurred at reproductive phases that could not be confirmed. The reason for this was that these animals had been diagnosed pregnant previously and had returned to estrus. The milk sampling for these animals had been discontinued when they were confirmed pregnant at around d 30 post-AI. Thus, no progesterone profiles led up to these activity clusters and they were excluded from further analysis.

\section{Definition of Terms}

The traits used to monitor physical activity and reproductive state of the cows are in Table 1. 

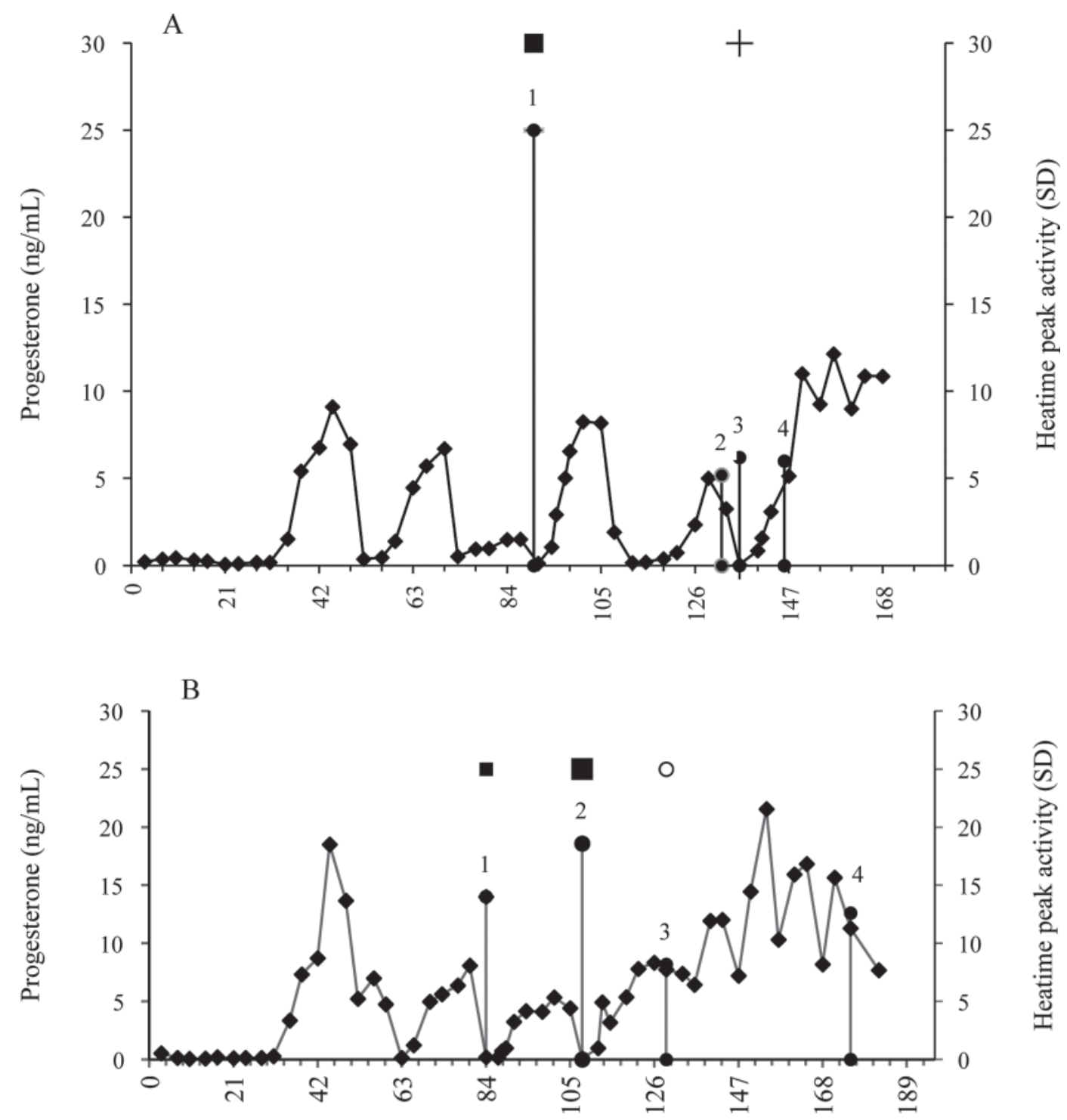

Days postpartum

Figure 1. Milk progesterone profiles $(\bullet$ and activity clusters $(\bullet)$ associated with different reproductive states. Activity cluster data are presented as standard deviations. Heatime (SCR Engineers Ltd., Netanya, Israel) activity clusters are labeled 1 to 4 . $\mathbf{\square}=$ Insemination with conception; $+=$ insemination and full-term pregnancy resulting; $\bigcirc=$ insemination while pregnant and still going to full term. In panel A, Heatime collar applied at d 51; in panel B, Heatime collar applied at d 72.

\section{Al and Conception Protocol}

The voluntary waiting period was normally $35 \mathrm{~d}$ postpartum, after which cows were submitted for AI when an activity cluster was detected by Heatime. One cow had her first AI on d 31. The following is a breakdown of the range of DIM for each AI $(n=145)$ carried out during a preovulatory follicular phase identified by an activity cluster: first AI: 31 to 168 DIM (n $=68)$, second AI: 50 to 178 DIM $(\mathrm{n}=52)$, third AI:
73 to 182 DIM $(\mathrm{n}=19)$, and fourth AI: 125 to 180 DIM $(\mathrm{n}=6)$. Inseminations were carried out either on the same day or the day after the activity cluster, using the a.m.-p.m. rule. The distributions of these inseminations were April (22), May (42), June (41), and July (40). The farmer did not record estrous behavior by observation, but generally relied on Heatime activity clusters for AI. When the monitor identified an animal with an activity cluster, she was presumed in estrus and AI using the a.m.-p.m. rule. Approximately 

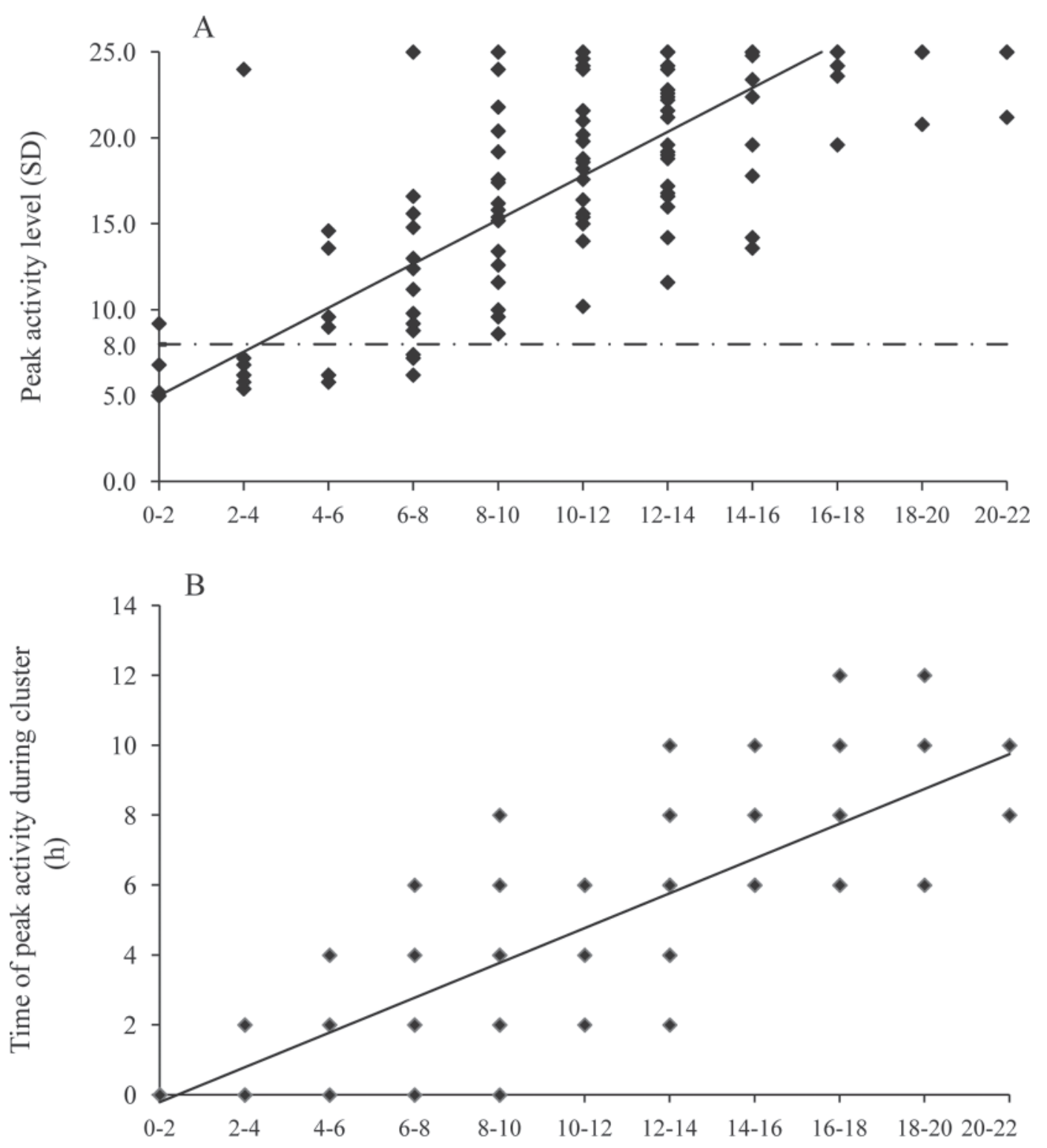

Duration of activity clusters (h)

Figure 2. A) The relationship between peak activity and duration of each activity cluster associated with a preovulatory follicular phase (n $=159$ ). The trend line (solid line) depicts the positive linear relationship between duration and peak activity for activity clusters. The horizontal line (dashed-dotted line) represents the threshold level set by the manufacturer for strong estrous activity (i.e., 8 SD). B) The relationship between the time of occurrence of peak activity during activity clusters with the duration of these activity clusters (solid line), which are associated with preovulatory follicular phases $(n=159)$.

30 d post-AI, transrectal ultrasonography was used to establish if the animal was pregnant. One hundred fifty-six AI were carried out during a preovulatory follicular phase, of which 9 were not associated with an activity cluster; another AI was carried out $2 \mathrm{~d}$ after the activity cluster and a further AI was carried out 1 $\mathrm{d}$ before the activity cluster.

\section{Statistical Analyses}

All analyses were performed using the Statistical Analysis System 9.1 software package (SAS Institute Inc., Cary, NC). Analysis of the first hypothesis involved the use of 3 separate analyses. In the first analysis, the F-test was used to compare the mean peak activity levels 
Table 1. Definition of terms associated with Heatime (SCR Engineers Ltd., Netanya, Israel) and the reproductive states of cows determined by progesterone concentrations from twice-weekly milk samples

\begin{tabular}{|c|c|}
\hline Term & Definition \\
\hline Activity level & $\begin{array}{l}\text { Rate of head and neck movement, measured in SD above the established } \\
\text { baseline for the cow (average movement rate over previous } 7 \mathrm{~d} \text { ) }\end{array}$ \\
\hline Peak activity level of an activity cluster & $\begin{array}{l}\text { Peak activity was determined as the highest } 2 \text {-h SD block within a } \\
\text { cluster of high activity that corresponded to the } 8 \text { - } \mathrm{h} \text { SD being } \geq 5 \text { times } \\
\text { the SD for the equivalent time period over the previous } 7 \mathrm{~d}\end{array}$ \\
\hline Preovulatory follicular phase & $\begin{array}{l}\text { The period where progesterone concentration decreased to }<0.6 \mathrm{ng} / \mathrm{mL} \text {. } \\
\text { Ovulation followed this phase, identified by a subsequent rise in progesterone } \\
\text { to } \geq 0.6 \mathrm{ng} / \mathrm{mL} \text { on } 2 \text { or more subsequent milk samples assayed }\end{array}$ \\
\hline Luteal phase & $\begin{array}{l}\text { The period of the estrous cycle during which a corpus luteum was producing progesterone. } \\
\text { This was identified by a series of milk progesterone concentrations } \geq 0.6 \mathrm{ng} / \mathrm{mL}\end{array}$ \\
\hline
\end{tabular}

of activity clusters associated with a high-progesterone luteal phase (the pregnant group and the regressing and developing corpora lutea). This was then repeated for the mean durations of activity clusters associated with these high-progesterone phases. Second, a comparison was made between the mean peaks and durations of clusters in those having high-progesterone phases (the amalgamated regressing and developing corpora lutea and pregnancy groups), those at the first ovulation postpartum, and those at subsequent ovulations using the F-test. Third, logistic regression was used to examine whether peak and duration of an activity cluster influenced the probability that an animal was in a preovulatory follicular phase and not a high-progesterone phase. For logistic regression analysis, the models used had all predictors included initially. The predictor with the highest $P$-value was removed and the model was rerun. This was repeated until all predictors remaining in the model were significant at $P<0.05$. A receiver operating characteristic (ROC) curve was used to assess the sensitivity and specificity of the logistic regression model. This was achieved by including in the model the option OUTROC $=$ ROC1 to create the output data set (ROC1) with the data necessary to plot an ROC curve (Cody and Smith, 1997). An ROC curve is a graphic plot of the sensitivity versus 1 - specificity. At predetermined thresholds for both peak activity level and duration, sensitivity was defined as the fraction of true preovulatory follicular phases identified by an activity cluster, out of the total number of preovulatory follicular phases identified at the different peak activity levels and durations examined. The same criteria held for specificity, which was defined as the fraction of non-preovulatory phases that were not associated with an activity cluster. Therefore, 1 - specificity was the proportion of non-preovulatory follicular phases associated with an activity cluster (i.e., false positives). If the area under the ROC curve was considered as a measure gauging the probability of detection by Heatime of a preovulatory follicular phase, then the closer the area

Table 2. Characteristics of low-progesterone $\left(\mathrm{P}_{4}\right)$ reproductive states associated with, or without, activity clusters in the postpartum period of dairy cows and characteristics of high- $\mathrm{P}_{4}$ luteal phase reproductive states associated with activity clusters in the postpartum period of dairy cows

\begin{tabular}{|c|c|c|c|c|}
\hline \multirow[b]{2}{*}{$\begin{array}{l}\text { Reproductive } \\
\text { state of } \operatorname{cow}^{1}\end{array}$} & \multicolumn{4}{|c|}{ Characteristic of activity clusters } \\
\hline & $\begin{array}{l}\text { Total no. of } \\
\text { reproductive states }\end{array}$ & $\begin{array}{l}\text { No. of reproductive states } \\
\text { with activity clusters }\end{array}$ & $\begin{array}{l}\text { Mean peak } \\
\text { activity (SD) }\end{array}$ & $\begin{array}{c}\text { Mean } \\
\text { duration }(\mathrm{h})\end{array}$ \\
\hline First preovulatory follicular phase postpartum & 37 & 11 & 14.8 & 8.4 \\
\hline Subsequent preovulatory follicular phase & 184 & 148 & 19.3 & 10.8 \\
\hline Anovulatory phase & 7 & 7 & 8.8 & 3.4 \\
\hline (1) Developing corpus luteum & 17 & 17 & 8.45 & 3.76 \\
\hline (2) Regressing corpus luteum & 14 & 14 & 8.03 & 3.1 \\
\hline (3) Persistent corpus luteum & 4 & 4 & 6.0 & 0.5 \\
\hline (4) Pregnant & 44 & 44 & 7.8 & 2.8 \\
\hline
\end{tabular}

${ }^{1}$ See Table 1 for definitions of reproductive states. 
under the curve was to 1 , the better the prediction. The second hypothesis was tested with the use of logistic regression to examine which factors influenced the probability of a preovulatory follicular phase being detected by Heatime. The predictors were measures that were indicators of health, production, and physiological status. Each time the model was run, the trait with the least significant $P$-value was removed. The model was rerun until only significant parameters were left.

For the third hypothesis, logistic regression was used to analyze whether 3 factors influenced the success rate of AI. These 3 predictors were 1) the timing of AI in relation to time of occurrence of an activity cluster, 2) the peak activity level, and 3) the duration of a cluster. The responses tested were 1) the probability of AI leading to a conception, 2) the probability of AI leading to a full-term pregnancy, and 3) the probability of conception leading to a full-term pregnancy.

\section{RESULTS}

\section{The Number of Activity Clusters During Different Reproductive States}

Two hundred forty-five activity clusters were detected by Heatime; 7 were associated with anestrus, 11 with the preovulatory follicular phases associated with first ovulation postpartum, and 148 with the subsequent preovulatory follicular phases postpartum (Table 2). These associations were detected by analysis of milk progesterone concentrations. A further 79 activity clusters were identified coinciding with high milk progesterone concentrations $(>0.6 \mathrm{ng} / \mathrm{mL})$ and occurring during a luteal phase (Table 2). Included in this group were 31 activity clusters associated with developing and regressing corpora lutea, 44 with pregnancy and 4 with persistent corpora lutea (Figure $1 \mathrm{~A}$ and B). Of the 44 clusters noted in pregnant cows, 10 pregnancies had 2 activity clusters each and the remaining 34 pregnancies had 1 activity cluster each. Across all cows, 221 preovulatory follicular phases were detected based on milk progesterone profiles. The distribution of these preovulatory follicular phases was April (35), May (70), June (68), and July (48). Of these, 159 were associated with the occurrence of an activity cluster and 62 that occurred were not. Of 37 first preovulatory follicular phases postpartum, only 11 (30\%) were identified by an activity cluster. During subsequent preovulatory follicular phases postpartum, 148 (80.4\%) of 184 were confirmed by an activity cluster, leaving only $36(19.6 \%)$ not detected when using the current commercial settings for activity cluster thresholds.

When using the current commercial settings for activity cluster thresholds, Heatime successfully detected
$72 \%(159 / 221)$ of preovulatory follicular phases, missed $28 \%(62 / 221)$ of preovulatory follicular phases, and incorrectly identified $32 \%(79 / 245)$ of activity clusters that occurred during high-progesterone phases.

\section{Characteristics of Activity Clusters and Their Associated Reproductive States}

Activity clusters were characterized by how their peak activity intensity and duration of activity were influenced by their reproductive state at the time of their occurrence. The mean peak activity level and mean duration of activity clusters are in Table 2 . Those activity clusters detected during anestrus and those associated with a persistent corpus luteum were not statistically analyzed as their numbers were too small. Preovulatory follicular phase activity clusters associated with subsequent postpartum ovulations had higher $(P<$ $0.0001)$ mean peak activity levels (19.3 SD) and mean durations $(10.8 \mathrm{~h})$ than those occurring with first postpartum ovulations (14.8 SD and $8.4 \mathrm{~h}$, respectively). In relation to activity clusters detected during luteal phase periods of elevated progesterone concentration, no difference was observed between the mean peak activity level and mean duration for both the pregnant group and the regressing and developing corpora lutea group $(P>0.1)$. Both of the high-progesterone luteal groups had lower $(P<0.0001)$ mean peak activity levels (pregnant group $=7.87 \mathrm{SD}$ and luteal phase group $=8.24 \mathrm{SD}$ ) and mean durations (pregnant group $=2.8$ $\mathrm{h}$ and luteal phase group $=3.43 \mathrm{~h}$ ) than those activity clusters detected in periods of low progesterone and associated with preovulatory follicular phases (Figure 3A and B). Thus, the activity cluster traits were affected by the reproductive state of the animal with mean peak activity and cluster duration being decreased when detected in the luteal phase or during pregnancy. On comparison of the mean peak activity level for all 4 groups $(F$-statistic $=61.07 ; P<0.0001)$ and of their mean durations $(F$-statistic $=50.7 ; P<0.0001)$, it was concluded that all 4 endocrine states did not have the same activity cluster characteristics.

Overall, for all 245 activity clusters, a correlation existed between peak activity level intensity and cluster duration $(\mathrm{r}=0.86 ; P<0.0001)$. This held for the 159 preovulatory follicular phases $(\mathrm{r}=0.76 ; P<0.0001)$ as well as the 86 remaining clusters $(\mathrm{r}=0.78 ; P<$ 0.0001). For the 159 activity clusters associated with a preovulatory follicular phase, the longer the duration of the activity cluster, the higher the peak activity intensity that was recorded (Figure 2A). A meager relationship existed between the duration of a cluster and the time of occurrence of the peak activity level. The time to peak activity was just before halfway through a 

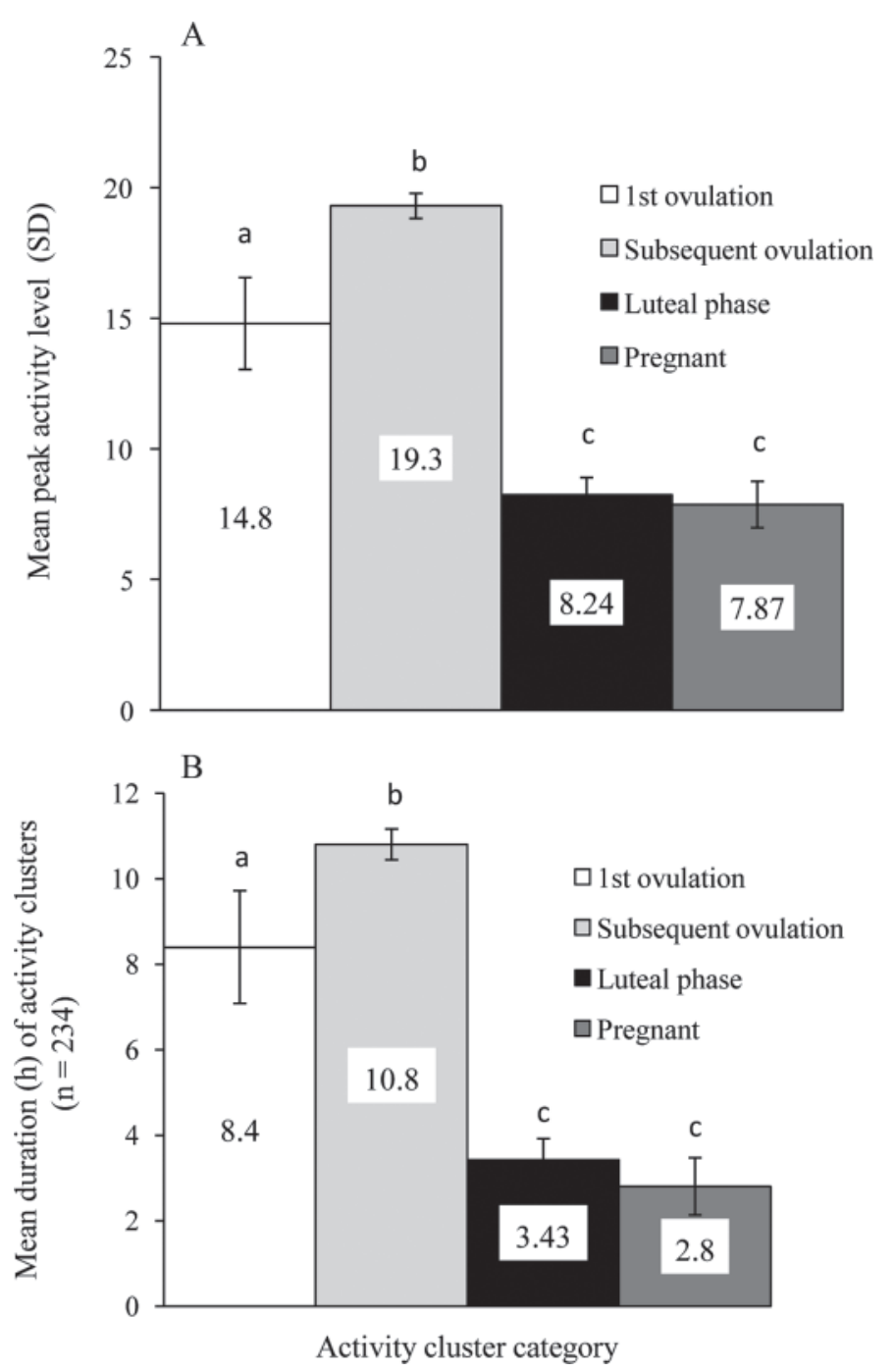

Figure 3. A) The mean \pm standard error of the means peak activity level of activity clusters was influenced by the endocrine state in which they occurred and B) mean \pm standard error of the means duration of activity clusters was influenced by the endocrine state in which they occurred. Means within a bar chart with different letters $(\mathrm{a}-\mathrm{c})$ differ $(P<0.0001)$

cluster, but this could vary. With a duration of activity clusters of $<10 \mathrm{~h}$, a peak activity level occurred at any time from the start of an activity cluster right through to the end of the cluster. In activity clusters of $>10 \mathrm{~h}$ in duration, a peak activity level was never seen at the start or end of a cluster (Figure 2B).

\section{Relationships Between Activity Cluster Measures and Accuracy of Identification of Preovulatory Follicular Phases}

Including activity clusters associated with pregnant cows, 234 activity clusters were analyzed in a model to examine whether peak and duration of an activity cluster influenced the probability that an animal was in a preovulatory follicular phase and not a luteal phase. As peak activity intensity increased by a score of 1 , the odds of it being associated with a preovulatory follicular phase increased by $33 \%$ (odds ratio $=1.33 ; P<$ 0.0001 ; Figure 4A). Duration of a cluster was a significant factor, with an increase of 2-h duration resulting in the odds of it being associated with a preovulatory follicular phase improving by $92 \%$ (odds ratio $=1.92$; $P<0.0001$; Figure 4B). The ROC curve analysis was used to assess the accuracy of using a threshold of between 5 to 8 standard deviations above threshold peak activity level intensity. In ROC curve analysis, the best possible prediction would yield a point in the upper left corner or coordinate $(0,1)$ of the ROC space. This would represent 100\% sensitivity (all preovulatory follicular phases identified by an activity cluster) and $100 \%$ specificity (no luteal phase identified by an activity cluster). The nearest point to this was for peak activity intensity of 13 standard deviations. This gave an estimated probability of $71 \%$ that a preovulatory follicular phase was identified by the activity cluster. On the ROC curve, it was depicted by a sensitivity value of 0.79 , which indicated that $79 \%$ of preovulatory follicular phases would be correctly identified. A reading for 1 - specificity of 0.0667 indicated that with a specificity of $93.3 \%$, only $6.7 \%$ of luteal phases would be falsely identified as preovulatory follicular phases at a peak activity intensity threshold of 13 . In the ROC curve analysis, the area under the curve was 0.887 . On examination of the ROC curve established for the duration of an activity cluster, where both borderline and strong intensity activity clusters were included, a threshold of 6 to $8 \mathrm{~h}$ would give an estimated probability of $63.5 \%$ of an activity cluster identifying a preovulatory follicular phase. It would correctly include $87.5 \%$ of preovulatory follicular phases (sensitivity = 0.875 ) and exclude $78.7 \%$ of luteal phases (specificity $=$ 0.787 ), but incorrectly include $21.3 \%$ of luteal phases (1 - specificity). In the ROC curve analysis, the area under the curve was 0.884. Frequency distribution histograms for preovulatory follicular phases (Figure 5A) and an amalgamated luteal group consisting of developing and regressing corpora lutea and pregnant phases (Figure 5B) show that neither had a normal distribution curve. When the groups were compared with durations of 6 to $8 \mathrm{~h}$, the majority of luteal phases were eliminated and the majority of preovulatory follicular phases were included.

Exclusion of borderline peak activity intensities of 5 to 8 standard deviations resulted in 164 activity clusters remaining. These consisted of 142 preovula- 
A

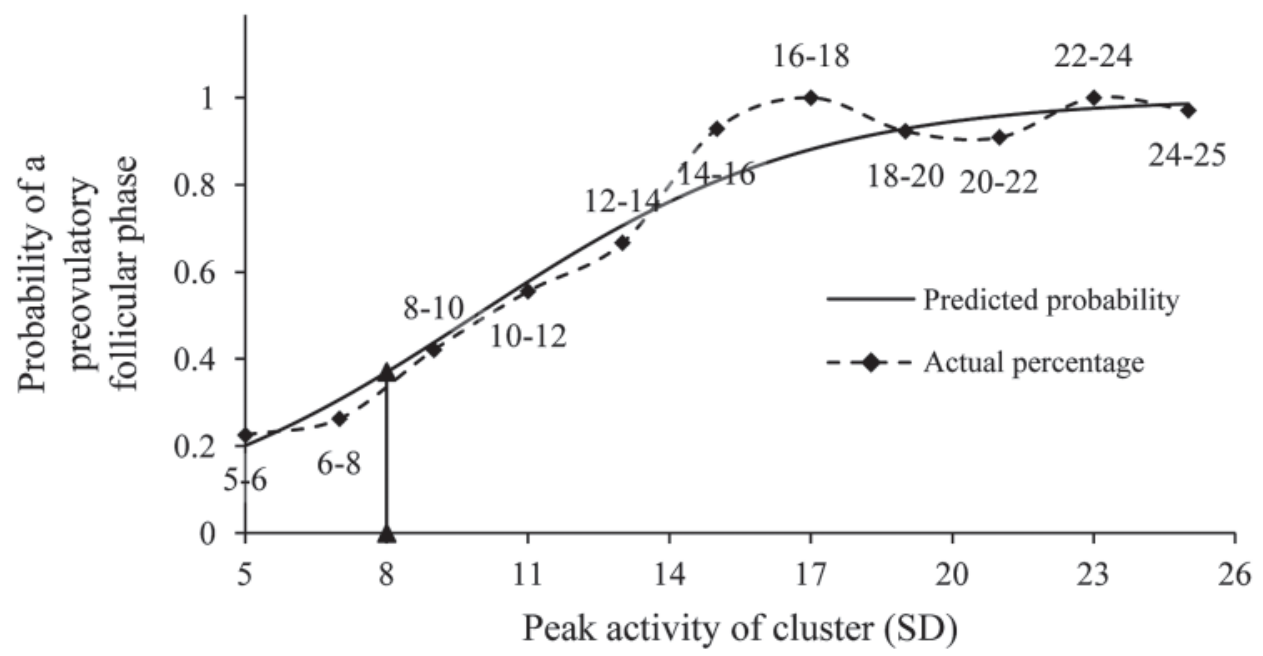

B

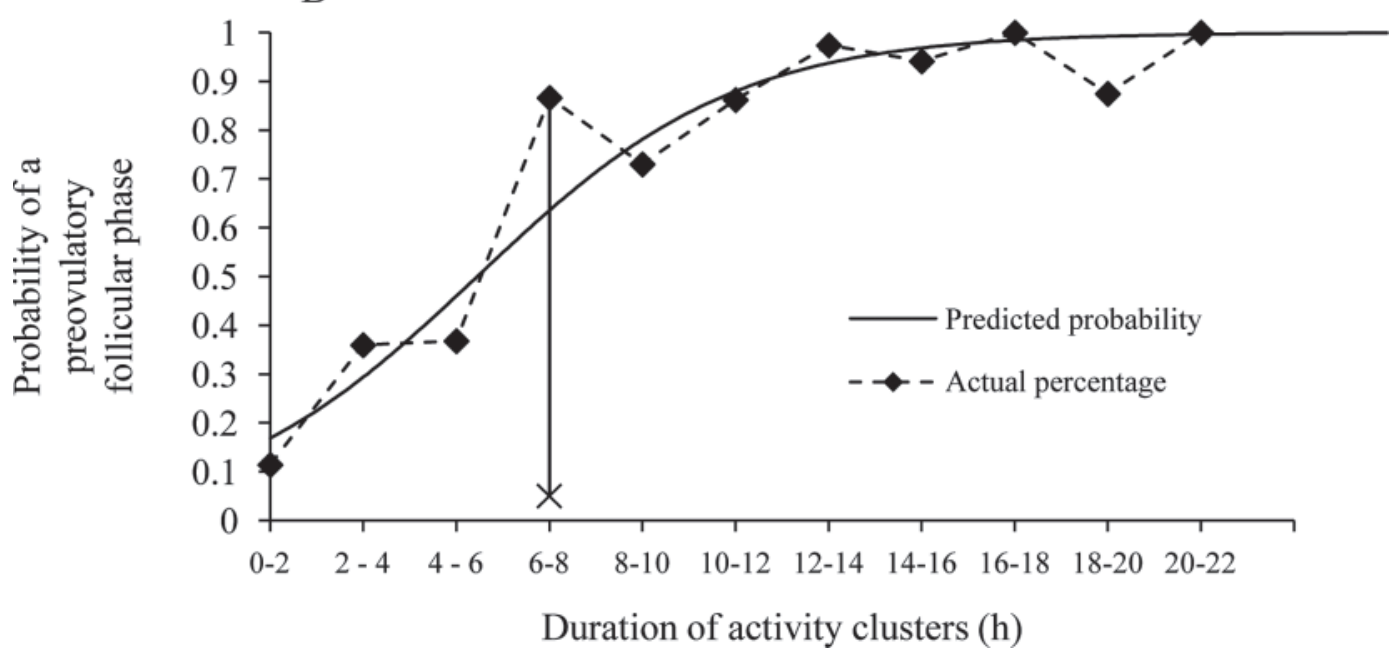

Figure 4. A) The peak activity level of an activity cluster influenced the probability that it was associated with a preovulatory follicular phase $(\mathrm{n}=159)$ and not a luteal phase \{clusters associated with luteal phase concentrations of progesterone, developing and regressing corpora lutea, and pregnant cows [i.e., false positive identification by Heatime (SCR Engineers Ltd., Netanya, Israel)]; $\mathrm{n}=75\}$. Both borderline and activity clusters are included. There was a 37\% predicted probability of an activity cluster identifying a preovulatory follicular phase at a threshold of 8 standard deviations. B) The duration of an activity cluster influenced the probability that it was associated with a preovulatory follicular phase cluster $(\mathrm{n}=159)$ and not a luteal phase [clusters associated with luteal phase concentrations of progesterone, developing and regressing corpora lutea, and pregnant cows (i.e., false-positive identification by Heatime); $\mathrm{n}=75]$. Both borderline and activity clusters are included; $87 \%$ of activity clusters lasting 6 to $8 \mathrm{~h}$ identified a preovulatory follicular phase.

tory follicular phases, 8 developing and regressing corpora luteal phases, and 14 pregnant phases. Using a peak activity level of $>8$ intensity as a predictor in the model, the odds of an activity cluster identifying a preovulatory follicular phase increase by $30 \%$ for each unit increase in peak activity intensity (odds ratio $=$ 1.3; $P<0.0001)$. An ROC curve analysis showed that at a peak activity intensity of 13.6 standard deviations, there was an estimated probability of a $75.6 \%$ chance of being in a preovulatory follicular phase and of $88 \%$ of these preovulatory follicular phases being correctly identified. The associated specificity of $77.3 \%$ indicated that $22.7 \%$ of activity clusters would be in a luteal phase, incorrectly identified as being in a preovulatory follicular phase. In the ROC curve analysis, the area under the curve was 0.825 . Using duration of an activity cluster with a peak activity level intensity above 8 standard deviations in the model, as duration increased by $2 \mathrm{~h}$, the odds of a preovulatory follicular phase being detected increased by $85 \%$ (odds ratio $=1.85 ; P$ $<0.0001)$. On examination of the graph in the ROC curve chart, it was found not near the left-hand corner 
A

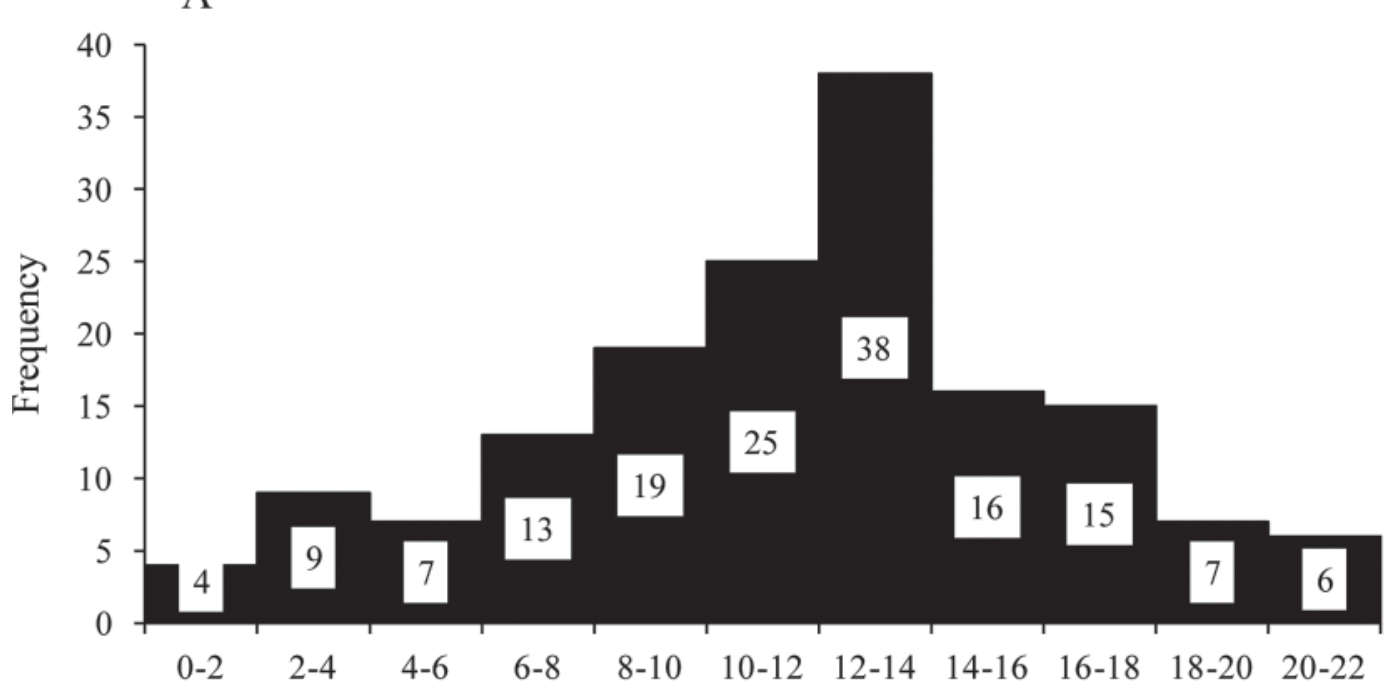

B

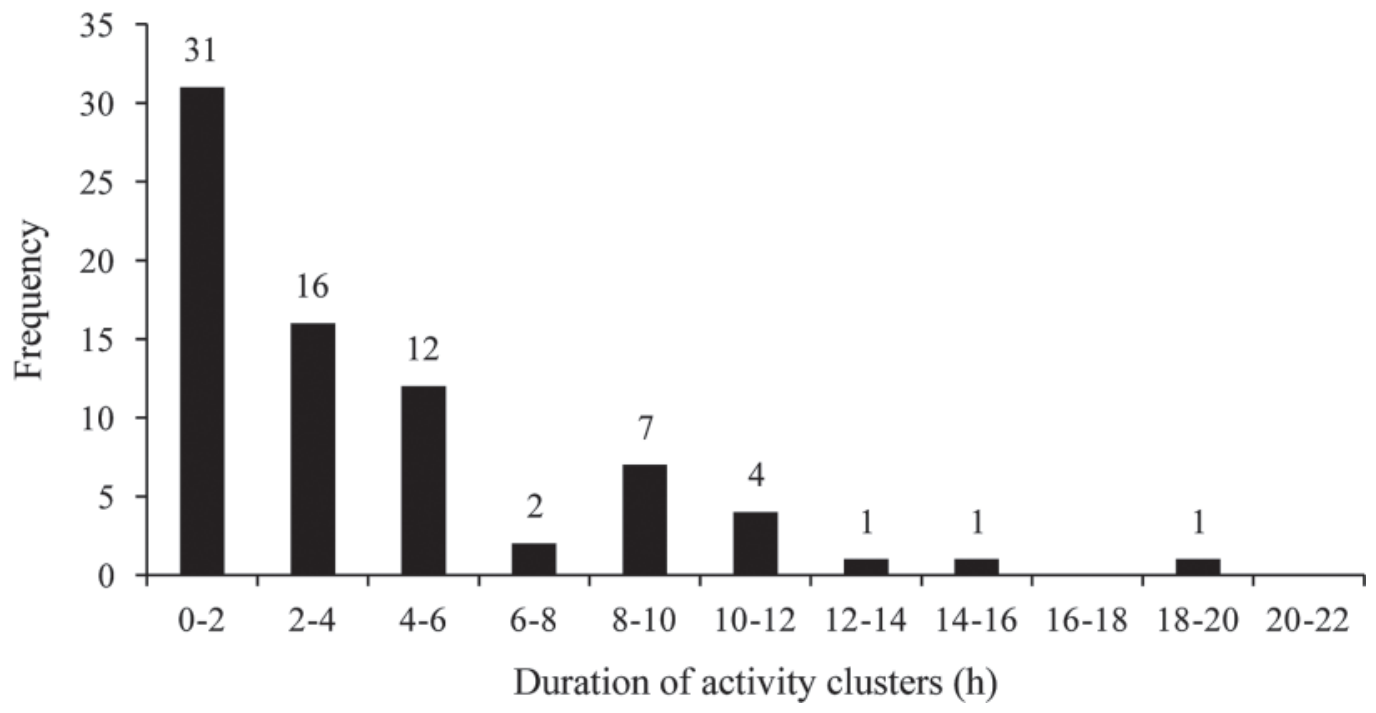

Figure 5. A) Frequency distribution of activity clusters categorized by their durations (clusters associated with valid preovulatory follicular phases only; $\mathrm{n}=159$ ). B) Frequency distribution of activity clusters categorized by their duration \{clusters associated with luteal phase concentrations of progesterone, developing and regressing corpora lutea, and pregnant phases [i.e., high-progesterone phases falsely identified by Heatime (SCR Engineers Ltd., Netanya, Israel)]; $\mathrm{n}=75\}$.

of the chart, showing that at a duration threshold of 6 to $8 \mathrm{~h}$, there was an estimated probability of a $71.7 \%$ chance of being in a preovulatory phase, with $95.7 \%$ of these preovulatory follicular phases correctly identified. The associated specificity of $50 \%$ indicated that $50 \%$ of activity clusters would be in a luteal phase, incorrectly identified as being in a preovulatory follicular phase. This model did not fit as well as when both the borderline and strong intensity clusters were included. The graph line runs near the chance line. Points below this diagonal line would represent results of a low predictor.
In the ROC curve analysis, the area under the curve was 0.8 .

\section{Factors that Affect the Ability of an Activity Cluster to Detect a Preovulatory Follicular Phase}

Four factors had a significant relationship with the probability of a preovulatory follicular phase $(\mathrm{n}=212)$ being identified by an activity cluster. First, a second or subsequent preovulatory follicular phase had 8.23 times better odds of being identified by an activity cluster 
than a first postpartum preovulatory follicular phase (95\% CI: 3.51-19.257, $P<0.0001$; Table 3). Second, cows with higher BCS at the time of a preovulatory follicular phase were more likely identified by an activity cluster. The odds of the preovulatory follicular phase being identified improved by a factor of 1.383 (CI: $1.027-1.863 ; P=0.0327$ ) for each additional 0.25 BCS unit (Table 3). Third, in the absence of a uterine infection, a preovulatory follicular phase had 3.6 times better odds (CI: $1.625-8.46, P=0.0018$ ) of being detected by an activity cluster than if the preovulatory follicular phase were associated with a uterine infection (Table 3). Fourth, the lower the yield of a cow at the time of her preovulatory follicular phase, the more likely it was detected by an activity cluster. Thus, if she was producing $10 \mathrm{~kg}$ less than another cow that was also in a preovulatory follicular phase, the odds of her preovulatory follicular phase being identified by an activity cluster were greater by $67 \%$ (odds ratio for a $-10-\mathrm{kg}$ difference in yield $=1.67$; CI: $1.016-2.764$; $P=0.0432$; Table 3). The following factors, placed in order of removal from the model did not influence the ability of activity clusters to detect preovulatory follicular phases: 1) nearest record of milk protein to the time of occurrence of the preovulatory follicular phase (from $-14 \mathrm{~d}$ before and up to $4 \mathrm{~d}$ after the preovulatory follicular phase; $P=0.9957) ; 2$ ) decrease in BCS from calving to $\mathrm{d} 42$ postpartum $(P=0.8217) ; 3)$ SCC (mean of the 2 nearest counts to each preovulatory follicular phase; $P=0.8475)$; 4) lameness score of 1 or 2 versus a score of 3,4 , or $5(P=0.7322) ; 5)$ nearest record of butterfat percent $(P=0.5077) ; 6)$ dystocia score 1 versus score $>1(P=0.462) ; 7)$ lactation groups 1,2 , and $3(P=0.387) ; 8)$ calving injury $(P=0.1197) ; 9)$ retained placenta $(P=0.0795)$; and 10$)$ vaginal mucus character score (not infected vs. infected; $P=0.1362$ ). With regard to lameness score, of the 212 preovulatory follicular phases analyzed, 114 had a score of 1, 52 had a score of 2,41 had a score of 3,4 had a score of 4 , and 1 had a score of 5 . Lameness score 1 and 2 were combined as a non-lame group as defined by Sprecher et al. (1997) and this was compared with a score of $>2$ in the model.

From 212 preovulatory follicular phases examined postpartum, 148 were associated with subsequent preovulatory follicular phases and occurred in cows with no diagnosed uterine infection. With respect to these 148 subsequent preovulatory follicular phases, $84 \%$ of them were detected by the occurrence of an activity cluster (Figure 6A). In 28 subsequent preovulatory follicular phases, which occurred in cows with a diagnosed uterine infection, $57 \%$ were detected by the occurrence of an activity cluster. In Figure 6A, the graph displays how the 2 predictors, BCS and milk yield, had a significant relationship with an activity cluster's ability to detect a subsequent preovulatory follicular phase in cows with no uterine infection diagnosed. A significant difference existed in the detection of a preovulatory follicular phase by an activity cluster in cows with different BCS. A greater probability of a preovulatory follicular phase being detected by an activity cluster existed in cows with 0.25 units higher BCS $(P=0.033)$ or in cows producing $10 \mathrm{~kg}$ less milk $(P=0.04)$ than in other cows at the time of the preovulatory follicular phase. No interaction was found between the BCS and the milk yield of a cow $(P=0.15)$.

Statistical analysis using a frequency table to determine the number of activity clusters, of which 159 were associated with a preovulatory follicular phase, with a peak occurring during each of the twelve 2-h time blocks gave a chi-square statistic of $24.47(P=0.0109)$. This indicates that not all of the time points had the same frequency of activity cluster peaks occurring. No significant difference was observed in either mean peak ( $F$-statistic of $0.7 ; P=0.7348$ ) or mean duration ( $F$-statistic of $0.78 ; P=0.6569$ ) of activity clusters between the 12 time points examined. For data on the time of onset of activity clusters, no evidence existed for variation during a 24-h day. Activity clusters began at similar frequency at all time points (chi-squared test statistic of $9.83 ; P=0.5457)$.

Table 3. The confidence limits for the odds ratio for significant factors influencing the ability of an activity cluster to identify a preovulatory follicular phase

\begin{tabular}{|c|c|c|c|c|}
\hline Measure & $\begin{array}{l}\text { Odds } \\
\text { ratio }\end{array}$ & $\begin{array}{c}\text { Lower } 95 \% \\
\text { confidence limit }\end{array}$ & $\begin{array}{c}\text { Upper } 95 \% \\
\text { confidence limit }\end{array}$ & $P$-value \\
\hline Uterine infection absent vs. present & 3.6 & 1.63 & 8.46 & 0.0018 \\
\hline Subsequent vs. first preovulatory follicular phase & 8.2 & 3.5 & 19.26 & $<0.0001$ \\
\hline 10-kg decrease in milk yield ${ }^{2}$ & 1.7 & 1.02 & 2.76 & 0.0432 \\
\hline
\end{tabular}

${ }^{1}$ Cows with 0.25 units higher BCS at the time of the preovulatory follicular phase.

${ }^{2}$ Cows producing $10 \mathrm{~kg}$ less milk than other cows at the time of the preovulatory follicular phase. 
A

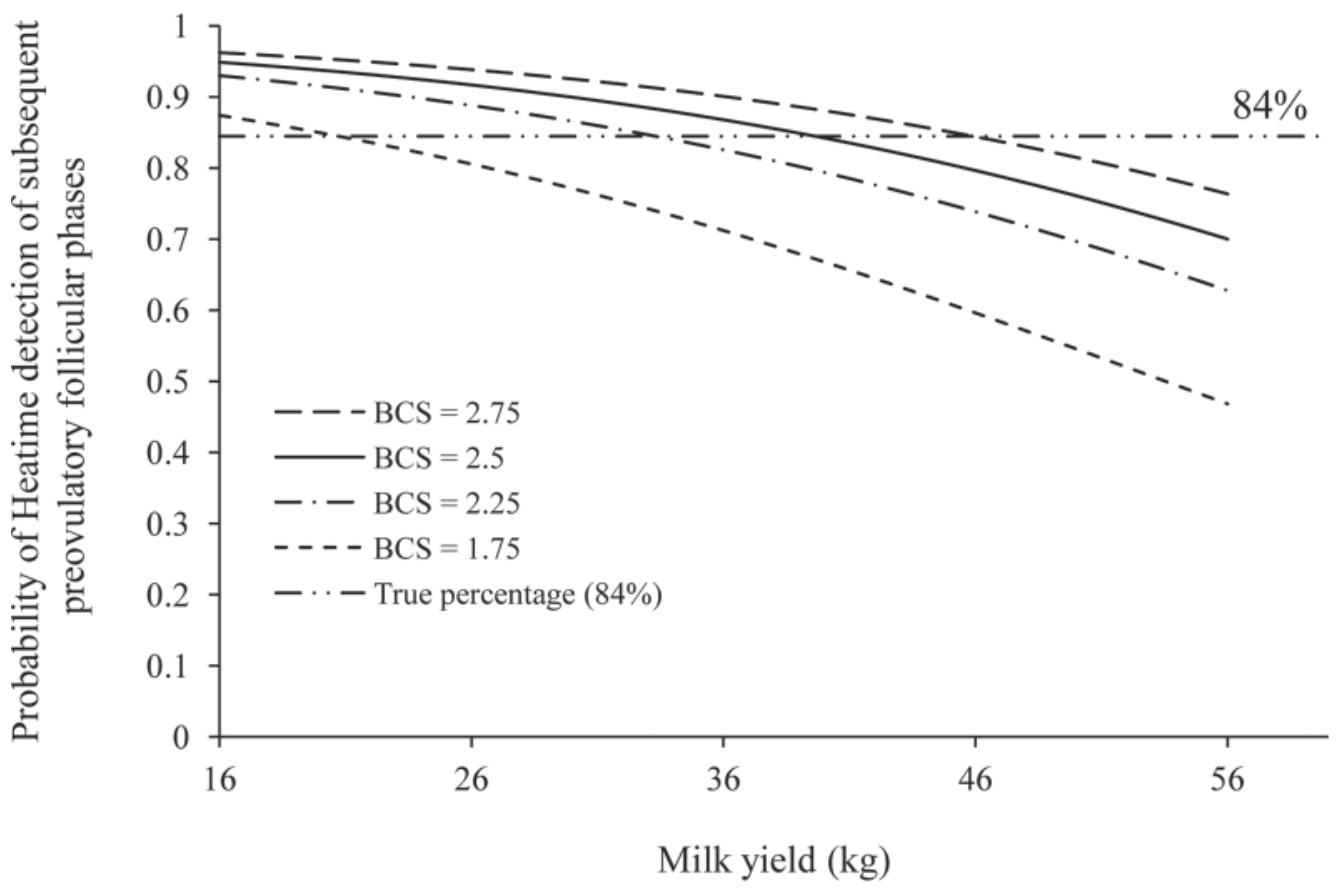

B

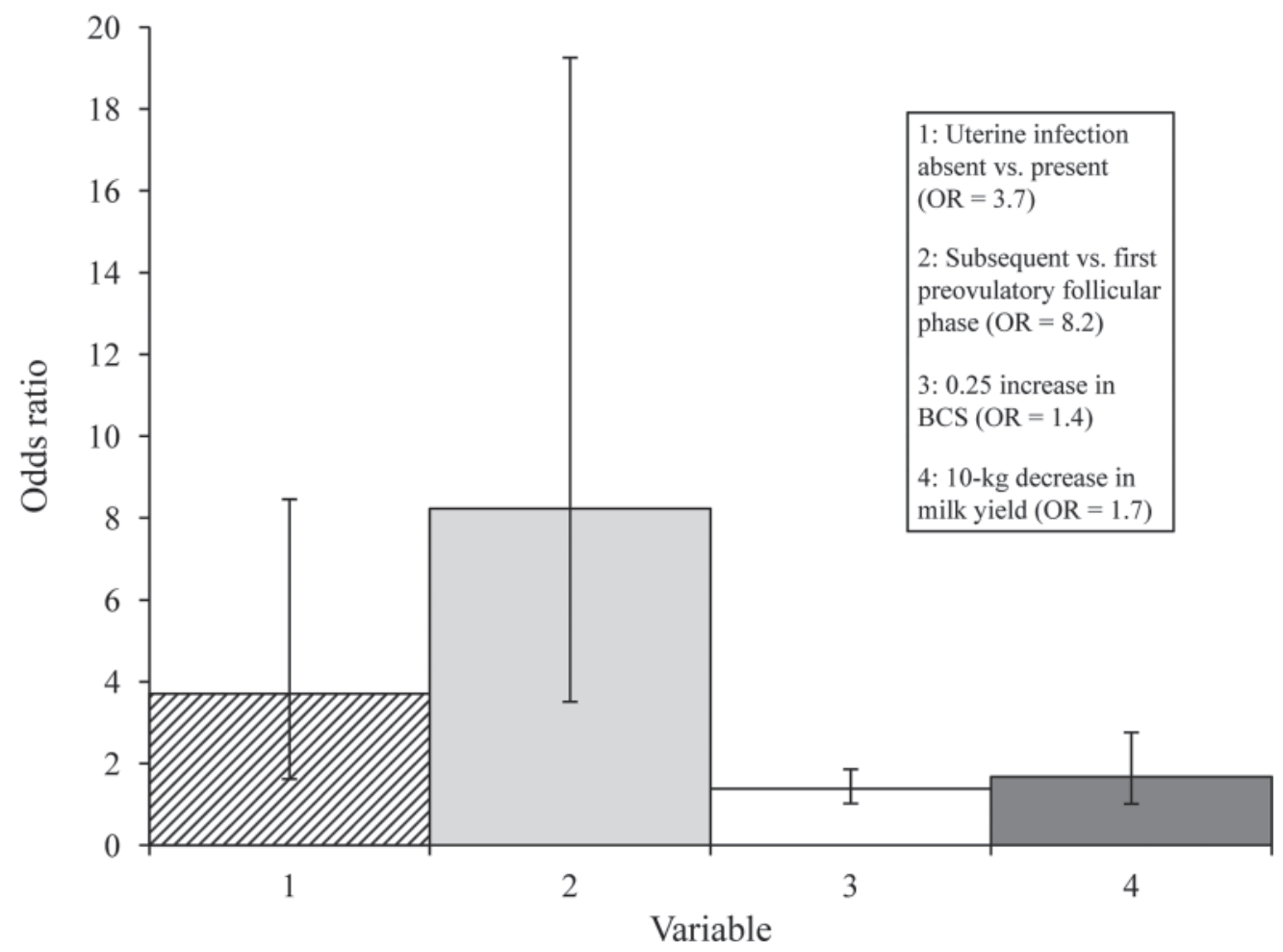

Figure 6. A) Effects of BCS and milk yield on the probability of Heatime (SCR Engineers Ltd., Netanya, Israel) detecting a subsequent preovulatory follicular phase in cows having no uterine infection $(\mathrm{n}=148$ subsequent preovulatory follicular phases identified with this status out of 212 preovulatory follicular phases examined). B) Bar chart showing the confidence limits for the odds ratio (OR) for significant factors influencing the ability of an activity cluster to identify a preovulatory follicular phase. 


\section{Characteristics of Peak Activity Patterns Associated with Activity Clusters and Effect on Conception Rates to Al}

The protocol for the timing of $\mathrm{AI}$ in relation to the time of occurrence of activity clusters was that when an activity cluster was identified at morning milking, the AI was carried out after that day's afternoon milking was finished. If the activity cluster was identified during an afternoon milking, then the AI was carried out after the following morning milking. One hundred fifty-six preovulatory follicular phases were associated with an AI, with $145 \mathrm{AI}$ occurring on the same day or day after a Heatime activity cluster. Of these 145 AI, 110 were carried out on the same day as a cluster, with 57 conceptions resulting (52\%). The remaining 35 AI were on the day after a cluster, with 12 conceptions being achieved (34.3\%). If AI occurred on the same day as an activity cluster, the odds of conception were $2.07(P$ $=0.07$ ) when compared with those carried out the day after an activity cluster. The problem with this analysis is that the exact time of when insemination occurred in relation to the time of the activity cluster was not recorded. Those carried out on the same day would have been done within $12 \mathrm{~h}$ of the activity cluster. Those carried out the following morning may have been 19 to $20 \mathrm{~h}$ after the activity cluster. Neither of the measures peak activity level $(P=0.5)$ nor duration of an activity cluster $(P=0.8)$ had a significant influence on the probability of an AI resulting in a conception. Thirtyeight AI resulted in a full-term pregnancy $(26.2 \%)$. The probability of a full-term pregnancy resulting from an AI was not influenced by timing of AI relative to the time of an activity cluster, peak activity level, or duration of the activity cluster $(P=0.39)$. From the 69 conceptions achieved, 38 went full term $(55 \%)$. When a conception occurred, the probability of a full-term pregnancy resulting was analyzed and none of the 3 measures influenced the result $(P=0.36)$.

\section{DISCUSSION}

The major findings were as follows: a higher peak activity level and longer duration occurred in activity clusters associated with the preovulatory follicular phase when compared with those associated with luteal phases. An increase in BCS, a lower milk yield, absence of a uterine infection, and whether the activity cluster was associated with a first or subsequent preovulatory follicular phase all influenced the probability of an activity cluster detecting a preovulatory follicular phase. The data on both peak and duration of an activity cluster could not be relied upon to predict possible fertility. Thus, cows with activity clus- ters were likely in a preovulatory follicular phase, but cows with longer-duration and higher peak intensity activity clusters were not necessarily more fertile. The activity clusters identified were not always associated with the preovulatory follicular phase of the estrous cycle. As was expected, the first preovulatory follicular phase postpartum went mainly undetected, with only $30 \%$ associated with an activity cluster. The resulting increase in progesterone concentration after the first ovulation resulted in a return to the normal expression of estrous behavior during subsequent preovulatory follicular phases (Rollin and Overton, 2007). This latter point was confirmed in this study with $80 \%$ of second and subsequent preovulatory follicular phases being associated with an activity cluster. Thirty-two percent of activity clusters occurred during a luteal phase with activity clusters in pregnant cows, totaling $56 \%$ of these or $18 \%$ of the total activity clusters recorded.

The shorter duration and lower peak activity intensity observed during the first preovulatory follicular phases compared with subsequent follicular phases was consistent with that observed in a study using HeatWatch. The first preovulatory follicular phase postpartum $(\mathrm{n}=$ 38) had a shorter duration of activity, with the number of times being mounted and the length of time standing to be mounted being shorter when compared with subsequent preovulatory phases $(\mathrm{n}=285)$ postpartum (Lopez et al., 2004). The activity clusters associated with luteal states (79 out of 245 clusters) as seen in this trial and others (Løvendahl and Chagunda, 2010) were mainly of borderline intensity and very short duration. It was found that the peak activity intensity of an activity cluster does influence the probability that it was associated with a preovulatory follicular phase and not a luteal phase. The expected antagonistic relationship between milk yield and fertility was apparent in this study, with a decrease in the odds of an activity cluster identifying a preovulatory follicular phase as milk yield increased. This antagonism between milk yield and estrous behavior was noted in a study where cows for which the system (HeatWatch) recorded no standing activity during estrus had a higher level of milk production than cows for which 2 or more standing events were recorded during estrus (Lopez et al., 2004). In the present study, it was noted that the probability of an activity cluster being associated with a preovulatory follicular phase increased if an increase in BCS occurred, if uterine infection was absent, and if the animal was at a second or subsequent preovulatory follicular phase. Also, the lower the milk yield at the time of a preovulatory follicular phase, the greater the probability of an activity cluster detecting it. Roche et al. (2007) reported a linear effect of the amount and rate of BCS drop postcalving on the odds of a cow being 
observed in estrus before the start of the herd breeding season, with lower odds of a cow exhibiting estrus with increasing amounts of body condition loss. Cows that lost 1 BCS unit (scale: 1 to 10) from calving to the planned start of mating had 0.69 times lower odds of being observed in estrus. Another study, looking at absolute BCS (using a scale of 1 to 5) at the time of the preovulatory follicular phase, found that the odds of an Afikim pedometer detecting a true estrus were decreased in cows with low BCS $(<2)$ compared with those with an acceptable BCS (odds ratio $=0.15, P=$ 0.08; Holman et al., 2011). The present study supports this finding where cows with higher BCS at the time of a preovulatory follicular phase were more likely identified by an activity cluster. Only 9 cows in the study group had a retained placenta, giving an overall incidence of $10 \%$. This supports an analysis of 652 calvings carried out by Sandals et al. (1979) who identified an incidence of $11 \%$. This incidence would be considered normal in a well-managed herd.

Activity clusters were effective as a means of identifying a preovulatory follicular phase. Peak activity level intensity and duration of a cluster were not predictors of the likelihood of an animal conceiving or going full term. Only the time of AI in relation to whether it was carried out on the same day or the day after an activity cluster influenced the probability of a conception occurring. This supports Esslemont and Watson (2008) who found that the best time to inseminate was within 4 to $18 \mathrm{~h}$ after the cow first stood to be mounted (with a 12-h delay producing the best conception rate). Conception rate decreased after a delay of $18 \mathrm{~h}$ (Esslemont and Watson, 2008). Cows in this study identified in a preovulatory follicular phase at the afternoon milking were only artificially inseminated after morning milking the following day at about 1030 to $1100 \mathrm{~h}$, which could be 19 to $20 \mathrm{~h}$ later.

\section{CONCLUSIONS}

The identification of an activity cluster was not always associated with a preovulatory follicular phase. All of the different reproductive states examined were significantly different in their activity cluster characteristics. In the preovulatory follicular phases identified by an activity cluster, as the peak activity intensity of an activity cluster increased, so did the duration of that activity cluster. The accuracy of identification of a preovulatory follicular phase improved as both peak activity intensity and duration of the associated activity cluster increased. Heatime should use a 6- to 8-h duration threshold and maintain the borderline peak activity threshold to retain the largest number of preovulatory follicular phases possible. Factors that im- proved the probability of an activity cluster identifying a preovulatory follicular phase were when a cow had no uterine infection, was in a subsequent preovulatory follicular phase postpartum, had an increase in BCS, and lower milk yield. The timing of $\mathrm{AI}$ in relation to the time of occurrence of the associated activity cluster did influence the probability of conception occurring, but not of the pregnancy going full term.

\section{ACKNOWLEDGMENTS}

This study was funded from a Science Foundation Ireland grant (07/SRC/B1156). The authors thank Progressive Genetics (Dublin, Ireland) for supplying the Heatime equipment for the trial period. Special thanks go to Fiona Carter and Pat Duffy of Lyons Estate Farm (Co. Kildare, Ireland), and the University College Dublin Hormone Assay Laboratory (Ireland) staff for their expert technical assistance. The comments and suggestions of our colleagues in the Reproductive Biology Research Cluster (University College Dublin) are greatly appreciated.

\section{REFERENCES}

Cody, R. P., and J. K. Smith. 1997. Multiple regression analysis. Pages 243-245 in Applied Statistics and the SAS Programming Language. 4th ed. Prentice Hall ed. Upper Saddle River, NJ.

Dillon, P., D. P. Berry, R. D. Evans, F. Buckley, and B. Horan. 2006. Consequences of genetic selection for increased milk production in European seasonal pasture based systems of milk production. Livest. Sci. 99:141-158.

Diskin, M. G., and J. M. Sreenan. 2000. Expression and detection of oestrus in cattle. Reprod. Nutr. Dev. 40:481-491.

Edmonson, A. J., I. J. Lean, L. D. Weaver, T. Farver, and G. Webster. 1989. A body condition scoring chart for Holstein dairy cows. J. Dairy Sci. 72:68-78.

Esslemont, R. J., and C. L. Watson. 2008. Oestrous behaviour and detection in to-day's dairy cows: The case for a fresh approach? Page 99 in Fertility in Dairy Cows: Bridging the Gaps. British Society of Animal Science, Penicuik, Midlothian, UK.

Holman, A., J. Thompson, J. E. Routly, J. Cameron, D. Grove-White, R. F. Smith, and H. Dobson. 2011. Comparison of oestrus detection methods in dairy cattle. Vet. Rec. 169:47-53.

Lopez, H., L. D. Satter, and M. C. Wiltbank. 2004. Relationship between level of milk production and estrous behavior of lactating dairy cows. Anim. Reprod. Sci. 81:209-223.

Løvendahl, P., and M. G. G. Chagunda. 2010. On the use of physical activity monitoring for estrus detection in dairy cows. J. Dairy Sci. 93:249-259.

Lyimo, Z. C., M. Nielen, W. Ouweltjes, T. A. M. Kruip, and F. J. C. M. van Eerdenburg. 2000. Relationship among estradiol, cortisol and intensity of estrous behavior in dairy cattle. Theriogenology $53: 1783-1795$.

Macdonald, K. A., G. A. Verkerk, B. S. Thorrold, J. E. Pryce, J. W. Penno, L. R. McNaughton, L. J. Burton, J. A. S. Lancaster, J. H. Williamson, and C. W. Holmes. 2008. A comparison of three strains of Holstein-Friesian grazed on pasture and managed under different feed allowances. J. Dairy Sci. 91:1693-1707.

Nebel, R. L., S. M. Jobst, M. B. G. Dransfield, S. M. Pansolfi, and T. L. Bailey. 1997. Use of a radio frequency data communication system, HeatWatch, to describe behavioral estrus in dairy cattle. J. Dairy Sci. 80(Suppl. 1):179. 
Peralta, O. A., R. E. Pearson, and R. L. Nebel. 2005. Comparison of three estrus detection systems during summer in a large commercial dairy herd. Anim. Reprod. Sci. 87:59-72.

Roche, J. R., J. M. Lee, K. A. Macdonald, C. R. Burke, and D. P. Berry. 2007. Associations between body condition score, body weight, and reproductive performance in seasonal-calving dairy cattle. J Dairy Sci. 90:376-391.

Roelofs, J. B., F. J. C. M. van Eerdenburg, N. M. Soede, and B Kemp. 2005. Various behavioral signs of estrous and their relationship with time of ovulation in dairy cattle. Theriogenology 63:1366-1377.

Rollin, E., and M. W. Overton. 2007. Energy balance and dairy cattle reproduction. Pages $7-13$ in Four-State Dairy Nutrition and Management Conference, Dubuque, IA. Four-State (IA, IL, MN, WI) Coop. Ext. and WI Agri-services Assoc., Madison, WI.

Royal, M. D., A. O. Darwash, A. P. F. Flint, R. Webb, J. E. Woolliams, and G. E. Lamming. 2000. Declining fertility in dairy cattle: Changes in traditional and endocrine parameters of fertility. Anim. Sci. 70:487-501.
Sandals, W. C. D., R. A. Curtis, J. F. Cote, and S. W. Martin. 1979 The effect of retained placenta and metritis complex on reproductive performance in dairy cattle-A case control study. Can. Vet. J. 20:131-135.

Sangsritavong, S., D. K. Combs, R. Sartori, L. E. Armentano, and M. C. Wiltbank. 2002. High feed intake increases liver blood flow and metabolism of progesterone and estradiol-17 $\beta$ in dairy cattle. J. Dairy Sci. 85:2831-2842.

Sheldon, I. M., and H. Dobson. 2004. Postpartum uterine health in cattle. Anim. Reprod. Sci. 82-83:295-306.

Sprecher, D. J., D. E. Hostetler, and J. B. Kaneene. 1997. A lameness scoring system that uses posture and gait to predict dairy cattle reproductive performance. Theriogenology 47:1179-1187.

Wiltbank, M., H. Lopez, R. Sartori, S. Sangsritavong, and A. Gümen. 2006. Changes in reproductive physiology of lactating dairy cows due to elevated steroid metabolism. Theriogenology 65:17-29. 